\title{
¿CÓMO FUNCIONA EL CEREBRO POLÍTICO? GUÍA DE COMUNICACIÓN POLÍTICA PARA ENTENDER A LOS VOTANTES Y A LA OPINIÓN PÚBLICA
}

How does the political brain work?

a political communication guide to understand voters and public opinion

\author{
$\underline{\text { Stefany Arteaga Márquez }}^{141}$
}

Fecha de recepción: 13 de mayo de 2018

Fecha de aceptación: 23 de mayo de 2018

Sumario: Resumen, Palabras Claves, 1. Introducción, 2. Estrategia Metodológica 3. Marco Teórico, 4. Análisis de las Teorías 5. Análisis del elector desde la Neurociencia 5.1. ¿Cómo piensan los electores? 5.2. Descripción del cerebro político, 6. Storytelling, herramienta de comunicación persuasiva, 7. Conclusiones, 8. Bibliografía.

\footnotetext{
141 Politóloga e internacionalista de la Universidad Militar Nueva Granada, Magister en Análisis Político de la Universidad Complutense de Madrid y Especialista en Opinión Pública y Mercadeo Político de la Universidad Javeriana. Consultora en gestión y desarrollo socioeconómico, con sólida experiencia en dirección de organizaciones sociales. Experta en formulación, ejecución, evaluación de proyectos, gestión de cooperación nacional e internacional y comunicación para el desarrollo. https://orcid.org/00000002-1767-0890 E-mail: stefanyarteagamarquez@gmail.com
} 


\section{COMO SE CITA ESTE ARTÍCULO (APA 6)}

Arteaga Martínez, Stefany (2018). ¿Cómo funciona el cerebro político? Guía de comunicación política para entender a los votantes y a la opinión pública. Revista Jurídica Mario Alario D’Filippo, Vol. X №. 20, pág. $187-212$.

\section{RESUMEN}

¿Cómo opera el cerebro de los ciudadanos a la hora de tomar la decisión electoral a favor de un candidato o partido político? y ¿cuál es la estrategia adecuada para que los políticos puedan conectar con éstos y ganar las elecciones? son las preguntas de investigación que se llevarán a cabo en el presente estudio, el cual pretende ser una guía de comunicación política.

\section{Palabras Claves}

Neurociencia, comunicación política, opinión pública, votantes, Storytelling.

\section{ABSTRACT}

How does the brain of citizens work when it comes to making the electoral decision in favor of a candidate or political party? And what is the right strategy for politicians to connect with them and win elections? These are the research questions that will be addressed in the present study, which aims to be a political communication guide.

\section{Key Words}

Neuroscience, political communication, public opinion, voters, Storytelling. 


\section{INTRODUCCIÓN}

Durante siglos, ha sido un gran reto para los científicos sociales explicar el comportamiento electoral, seguidos por un interés común, identificar los factores influyentes en las decisiones de los votantes, en virtud de comprender la estrategia más eficaz para conectar con ellos y ganar las elecciones.

Desde 1877, Charles Pierce, el fundador del pragmatismo y padre de la semiótica moderna, publica un análisis acerca de la conducta de la población frente al mensaje de la autoridad política y varios han sido los esfuerzos de las grandes escuelas de pensamiento político para resolver esta cuestión.

Ahora bien, los recientes hallazgos de la neurociencia, han permitido comprender que el votante es ciertamente más emocional que racional, y que en la decisión política hacia un partido o candidato, influyen factores radicales que en los anteriores estudios no se habían concebido.

Los estudios en neurociencia cada vez permiten conocer mejor los procesos cerebrales que están involucrados en la conducta y toma de decisiones de las personas, es por ello que desde este estudio se esgrimirá acerca del funcionamiento del cerebro y su aplicación en la conducta electoral.

Erik Richard Kandel científico estadounidense nacido en Viena, premio nobel en el año 2000, señaló que el siglo XXI sería el siglo del estudio de la mente, y efectivamente, el presente siglo ha estado dedicado a los estudios neurocientíficos involucrando incluso ciencias no médicas.

El cometido de la Neurociencia, es comprender con sus propias herramientas, los procesos mentales merced a los cuales percibimos, es por ello que desde la ciencia política, este estudio resulta ampliamente interesante, ya que los políticos siempre han estado interesados en comprender la mente de los electores y adquirir las técnicas más eficaces para conectar con ésta.

En el presente trabajo, se recogen estudios acerca del funcionamiento de las estructuras cerebrales y emocionales de los electores, y se realiza un análisis de la influencia de éstos en la victoria o derrota en las elecciones. Abordar este tema, es de gran relevancia ya que permitirá comprender las claves para que un partido o líder político conecte eficazmente con sus electores, lo cual impulsará a éstos a determinar las líneas de acción adecuada para la consecución de sus objetivos políticos. Las conclusiones encontradas en este estudio, servirán de guía para que políticos y sus estrategas desarrollen campañas políticas de éxito. 
El presente está estructurado en dos capítulos, el primero de ellos, está dedicado a la descripción y análisis del comportamiento de los votantes a partir de los estudios de neurociencia, se esgrimirán las funciones del cerebro y su relación con las decisiones política del elector, seguidamente, se encuentra el capítulo segundo, en el cual se explicará la ciencia del lenguaje relacionado con la mente, las emociones y la persuasión del votante, se analizará la herramienta de persuasión Storytelling.

\section{Estrategia Metodológica}

En este estudio, se pretende hacer una revisión documental, en la cual se analizarán los planteamientos de las distintas escuelas de pensamiento político, así como las postulaciones de la ciencia cognitiva y la neurociencia relacionadas con el comportamiento electoral, con el propósito de realizar una propuesta final que sirva de guía para comprender el comportamiento de los electores y realizar una comunicación política eficaz.

Se construirá primero un marco teórico sobre los principales enfoque, teorías y modelos explicativos del comportamiento electoral, se realizará una revisión de la literatura existente haciendo principal énfasis en los estudios de la Escuela Psicoanalítica y los hallazgos de la Neurociencia, se realizará un análisis crítico de las teorías, modelos y enfoques, generando un balance que permite describir sus características, similitudes y diferencias, de tal manera que se puedan extraer los principales elementos de los modelos que dan respuesta a la hipótesis del presente trabajo.

Finalmente, se presentarán las conclusiones del trabajo, en donde se identificarán los principales hallazgos y se valorará la contribución del mismo.

La hipótesis de esta revisión documental es que el comportamiento electoral está determinado por factores de tipo emocional que impactan fuertemente áreas del cerebro del elector, que generan empatía con el personaje político e influyen directamente en las decisiones del votante.

\section{Marco Teórico}

\section{Comportamiento Del Elector Desde Los Diferentes Enfoques}

Teniendo en cuenta que el objetivo del presente estudio es comprender cómo opera el cerebro de los ciudadanos a la hora de tomar la decisión electoral a favor de un candidato o partido político, así como identificar la estrategia adecuada para que los políticos puedan conectar con éstos, es preciso realizar una revisión desde las diferentes teorías del comportamiento electoral, lo cual permitirá identificar elementos claves que conducirán a dar respuesta a lo anterior. 
En primera instancia, es necesario comprender que al hablar de Comportamiento electoral se entiende, como la conducta que vincula a los ciudadanos con el poder, manifestada a través del sufragio electoral ${ }^{142}$.

Por otra parte, es preciso resaltar que en ciencia política, se usó por primera vez el término “comportamiento político" entendido en términos electorales, en 1937, por el trabajo del sueco Herbert Tingsten, titulado "Political Behavior: Studies in Election Statistics" (Peñas, 2010), no obstante desde 1877, se empieza a analizar el comportamiento de los seres humanos frente a la política, con la publicación realizada por el filósofo Charles S. Peirce del artículo "The Fixation of Belive", en el cual sustenta que la manera de conectar con la mentes de los individuos es mediante sus propios hábitos, costumbres, tradiciones y formas populares de pensamiento, en su análisis, esgrime dos métodos que influyen en las creencias de los individuos, estos son el método de la tenacidad y el método de la autoridad, el primero hace referencia al sistema de creencias que se adquieren de generación en generación; el segundo concierne a los valores de respeto y confianza que se tienen acerca de un individuo.

Por otra parte, las aproximaciones a los estudios relacionados con el comportamiento electoral siguieron en 1918 cuando el psicólogo, pedagogo y filósofo estadounidense Jonh Dewey, escribe el artículo "New Paternalism: Molding Public Opinion" en el cual señala que el ser humano simplifica su percepción en términos de sus preferencias, no obstante, señala que éste también es influenciado por los estereotipos que difunden los medios de comunicación, debido a que utilizan recursos que influyen en las emociones para recrear las imágenes del "mundo exterior" que la gente tiene en su cabeza (Combs \& Nimmo, 1998).

Es interesante mencionar los planteamientos del filósofo y periodista Walter Lippmann en su libro Public Opinion escrito en 1922, en el cual menciona el fenómeno de pseudorealidades, concerniente a la formación de realidades inexistentes en los ciudadanos partiendo de representaciones simbólicas, que se relacionan con las creencias preexistentes de tales individuos; asimismo, afirma que los medios de comunicación son formadores de pseudoambientes y pseudorrealidades ya que las noticias se estructuran basados en ciertas funciones ideológicas y económicas, y gracias a éstos los políticos pueden construir personalidades irreales. (Lippman, 1956).

Ahora bien, las principales teorías que han estudiado el comportamiento electoral han sido tres, basadas desde los enfoques sociológico, psicológico y racional, conocidas como la Escuela de

\footnotetext{
142 Definición comprendida desde los postulados de la politóloga mexicana Jaqueline Perschard, publicados en el año 2000 en el libro Léxico de la política, por los investigadores Laura Baca Olamendi, Judit Bosker Liwerant, Fernando Castañeda, Isidro H. Cisneros, y Germán Pérez Fernández del Castillo.
} 
Columbia, la Escuela de Michigan y La Teoría Racional del voto. A continuación se revisarán los planteamientos de estos enfoques.

\section{Escuela de Columbia}

La Escuela de Columbia contribuyó a darle congruencia empírica al enfoque sociológico, considerado por Teodoro Luque, el enfoque precursor de los estudios de comportamiento electoral. (Luke, 1996), este enfoque tuvo su primera vertiente en Francia a principios de siglo, estaba fundado en que el comportamiento electoral estaba determinado por las características sociales, demográficas, regionales y económicas de cierta comunidad, partiendo de la idea, que al tener características semejantes, éstas tienden a reflejar conductas electorales similares. Desde esta perspectiva la historia moderna sobre la investigación académica del voto iniciada en la Universidad de Columbia en 1940, dirigida por el sociólogo austriaco Paul Felix Lazarsfield, implementa por primera vez las técnicas de investigación cuantitativas para analizar el pensamiento y comportamiento de los electores, este trabajo señaló los factores diferenciadores en la recepción del mensaje, tales como la edad, el sexo, el entorno social, las experiencias pasadas y las influencias de los padres en la decisión del voto. (Bartels, 2008).

La escuela de Columbia afirma que la acción de votar es una acción de tipo social, en la obra de Lazarsfield "The People Choice" el sociólogo y fundador de esta escuela señala que "votar es una experiencia de grupo, resultado del impacto de factores sociales como: La clase, la renta, la profesión, la religión, el hábitat". (Lazarfield, 1944).

\section{Escuela De Michigan}

En octubre de 1948 Angus Campbell y un equipo de investigadores del Survey Reseacrch Center (SRC) de la Universidad de Michigan, elaboraron una propuesta que difería de los planteamientos de la escuela de Columbia, conocido como el modelo de Michigan, este modelo tiene sus fundamentos en el enfoque psicológico, concibe el voto, como un acto individual, motivado por percepciones y orientaciones personales.

La escuela de Michigan señala que el enfoque de Columbia, no tenía en cuenta el planteamiento de la psicología social, y basados en esta perspectiva, desarrollaron su estudio, sosteniendo en su tesis que el comportamiento electoral estaba determinado por los valores y las inclinaciones políticas que se aprendían a través de la socialización, (Peschard, 2000).

\section{Teorías Racionales Del Voto}

A finales de la década de 1950 la economía política propone una visión distinta y se plantea la hipótesis de que los individuos actúan de acuerdo con sus intereses, racionalizan la información que se les proporciona y tratan de sacarle la mayor utilidad posible. El enfoque racional concibe 
el voto como un acto individual que responde a situaciones particulares en las que se emite, es decir que no se explica por variables estructurales, sino por factores de corto plazo frente a los cuales el ciudadano reacciona (Peschard, 2000). Desde esta perspectiva se desprenden la teoría de elección racional de Anthony Downs apoyada posteriormente por otros autores como Kenneth Arrow, James M. Buchanan, Raymond Aron, Gordon Tullock y William Ricker.

Esta teoría sostiene que el comportamiento electoral del ciudadano está basado conforme al cálculo de utilidad esperada que realiza el votante, teniendo en cuenta las propuestas presentadas en la coyuntura particular, sopesando los costos y beneficios de cada una.

Ahora bien, luego de hacer el recorrido por las principales escuelas de análisis del comportamiento electoral, se han tenido en cuenta otras escuelas dedicadas al análisis del comportamiento de los seres humanos, que surgieron para estudiar los patrones de conducta en la sociedad y que hoy están cobrando relevancia en las Ciencias Políticas; éstas son la Escuela Psicoanalista y la Neurociencia.

\section{Escuela Psicoanalítica}

La Escuela Psicoanalítica es fundada por el reconocido científico Sigmund Freud, nacido en Viena en 1856, conocido como el arqueólogo de la mente. El psicoanálisis se ha dedicado en gran medida a explicar la estructura mental funcional y la existencia de procesos mentales inconscientes señalando el papel que estas juegan en la determinación de la conducta (Alcazar, 2011).

Una de las ideas centrales del psicoanálisis que cobran relevancia en este estudio, es la tesis de que gran parte de las percepciones, sueños, deseos y acciones del ser humano no puede ser procesado por el conocimiento consciente, sino por el inconsciente.

Los estudios del psicoanálisis permiten comprender que existen sistemas múltiples de memoria. Los estudios de la percepción y la memoria avalan la idea de que la mente tiene estructuras organizacionales que codifican la interpretación de los datos sensoriales y los llevan a los sistemas de la memoria, específicamente a la memoria de largo plazo, formando los modelos o esquemas mentales, que son estructuras altamente organizadas, derivadas de las experiencias pasadas, que interpretan las experiencias actuales y que influencian en las conductas futuras. (Alcazar, 2011).

\section{Estudios De Neurociencia}

La Real Académica De La Lengua Española, define la Neurociencia como Conjunto de disciplinas científicas y médicas que tienen como objeto de estudio el sistema nervioso, en particular en sistema nervioso central. 
Éste término se ha extendido en relación con la revolución terapéutica que provocó la psicofarmacología en el campo de la psiquiatría y con la introducción de nuevas técnicas que han hecho progresar los conocimientos sobre el sistema nervioso central (SNC), su funcionamiento normal y su patología ${ }^{143}$.

La neurociencia utiliza datos de diversos orígenes, subrayando tanto los puntos de vista morfológicos y fisiológicos como los de la bioquímica, la genética y la biología molecular, así como los resultados de las múltiples técnicas de exploración funcional de la actividad cerebral, desde la electroencefalografía hasta las llamadas técnicas por la imagen.

Eric Kandel afirma que la tarea de la Neurociencia es aportar explicaciones de la conducta en términos de actividades del encéfalo, explicar cómo actúan millones de células nerviosas para producir la conducta y cómo estas células están influidas por el medio ambiente. (Kandel, 2000)

Wolf Singer Director en el Max-Planck-Institute for Brain Research, en 1985 define la neurociencia como una ciencia que se nutre de cinco disciplinas, estas son, la anatomía, la embriología, la fisiología la farmacología, la psicología y recientemente se habla de la biología molecular y la genética, afirma que teniendo en cuenta esta multiplicidad de raíces se debe la diversidad de enfoques con que se aborda la neurociencia y el reto que constituye darle un cuerpo disciplinar unificado y abarcador.

Desde hace más de 30 años los neurocientíficos han utilizado las técnicas de imagen estructural del cerebro para estudiar su estructura relacionada con las funciones y conducta de los seres humanos, las técnicas utilizadas han sido principalmente la tomografía por emisión de positrones y más recientemente las tecnologías de resonancia magnética, éstas muestran las imágenes cerebrales que reflejan y rastrean las ondas en tiempo real e indican cómo se movilizan las reacciones emocionales.

Las Imágenes por Resonancia Magnética Funcionales (IRM) es una técnica no invasiva que utiliza campos magnéticos y su resonancia para obtener información sobre la estructura y áreas del cerebro que se activan ante situaciones o estímulos determinados, mediante éstas se puede observar el funcionamiento del cerebro.

Los avances en el conocimiento del cerebro humano han dado paso a la formación de nuevas disciplinas que conectan la neurociencia con otras ciencias aplicadas, de ahí que surge el tan

143 Tomado del Concepto de Neurociencia definido en el Estudio Introducción a la historia de las Neurociencias hasta finales del Siglo XIX, publicado en: http://www.neurociencias.org.es/intro.php 
sonado Neuromarketing, la Neuroeconomía, la Neuropedagogía, la Neuroética y recientemente varios científicos sociales están aplicándola a la política, denominándola Neuropolítica.

La Neuropolítica se entiende como una nueva disciplina capaz de comprender el cerebro de las personas en su condición de ciudadanos, electores o activistas, permite conocer mejor cómo funciona el cerebro y cómo el ciudadano articula las imágenes con valores y sentimientos y la forma en que se canalizan sus decisiones. (Rubí, 2012)

Con el método de la Resonancia Magnética Funcional (IRM) se logra observar el área que está siendo utilizada, a través del flujo de sangre que ilumina la pantalla y permite establecer las respuestas inconscientes que se tienen frente a los estímulos exteriores. (Sánchez, 2012)

Reconocidos científicos sociales americanos han estudiado el papel que juegan las emociones y el cerebro en el comportamiento de los electores, principalmente han sido el doctor en psicología política Drew Westen y el Neurolinguista George Lakoff.

Westen, profesor en el departamento de psicología y psiquiatría en la Universidad de Emory, fundador de Westen Strategies, firma consultora de asuntos políticos y corporativos, autor del libro The Political Brain: The Role of Emotion in Deciding the Fate of the Nation, en su estudio hace un análisis de las campañas políticas norteamericanas de los últimos 50 años, entre sus argumentos señala que "la experiencia demuestra que las elecciones se juegan en el mercado de las emociones y no en el "mercado de las razones", (Westen, 2008:52) Westen critica la teoría del actor racional, argumenta que cuando estrategias de campaña inician desde ésta teoría, los candidatos generalmente pierden.

George Lakoff profesor de ciencia cognitiva y lingüística de la Universidad de California, Berkeley, en su libro "The Political Mind" sintetiza su tesis en lo que él denomina, "Conocer el cerebro, para liderar las ideas", en el cual explica la razón por la cual muchos americanos votan en contra de sus intereses, argumenta que los americanos votan en relación a sus marcos mentales y que los republicanos han tenido éxito electoral ya que han enlazado su discurso al sistema de conceptos y valores de la sociedad Americana, y han logrado utilizar un lenguaje eficaz que penetre en las emociones del electorado y que se alinee a sus marcos mentales.

Relacionado con este enfoque, se encuentra a Frank Luntz, reconocido como uno de los mejores entrevistadores norteamericanos según Business Week, experto en el análisis de "Focus Group" para grandes grupos de comunicación, escritor del libro "Words that Works: It's Not What You Say, It's What People Hear", en el cual sintetiza su tesis, con el argumento que "tu puedes tener 
el mejor mensaje del mundo, pero la persona que lo recibe, siempre lo va a entender a través de sus propias emociones, preconceptos, prejuicios y creencias preexistentes".

\section{Análisis De Las Teorías Presentadas}

Teniendo en cuenta que la hipótesis de este estudio es que el comportamiento electoral está determinado por factores de tipo emocional que impactan fuertemente áreas del cerebro del elector, que generan empatía con el personaje político e influyen directamente en las decisiones del votante. Es preciso resaltar que el presente se regirá principalmente por los estudios y hallazgos de la Neurociencia y algunos planteamientos de la Escuela Psicoanalítica, no obstante en la revisión teórica se encontraron algunos planteamientos que serán claves en la relación con los hallazgos de las mencionadas.

En primera medida, los postulados de Charles Peirce en 1887 se relacionan de cierta forma con algunos de los postulados de la psicología cognitiva y algunas de los postulados neuropolíticos, ya que Charles Perice explica la importancia de conectarse con la mente de los individuos y esto debe realizarse mediante sus propios hábitos, costumbres, tradiciones y formas populares de pensamiento, que la neurociencia y el psicoanálisis conciben como marcos mentales.

Asimismo, se rescata uno de los planteamientos de Dewey, en el cual describe que el ser humano simplifica su percepción en términos de sus preferencias, no obstante es influenciado por recursos que impactan sus emociones, si bien la neuropolítica y el psicoanálisis demuestran que existen factores y recursos que impactan fuertemente áreas del cerebro que activan las emociones del elector y le permiten conectar con el personaje político, lo cual influye directamente en la conducta electoral.

Por otra parte, los hallazgos en neurociencia permitirán dar soporte a los postulados de la Escuela de Michigan que sostiene que los factores influyentes en la decisión electoral son las actitudes, percepciones, valores y creencias de los individuos.

Por otra parte, el presente estudio irá en contravía de los postulados de la Escuela de Columbia que manifiesta que los medios masivos de comunicación no pueden lograr cambios efectivos en el comportamiento de los votantes, considerando que éstos únicamente pueden generar un fuerte impacto en los inadaptados y marginales que no están integrados en partidos políticos, señalando que las campañas políticas y el uso de los medios de comunicación no cambian la conducta de los votantes, debido a que éstos deciden de acuerdo a su grupo de pertenencia, lo cual quiere decir que el nivel de movilidad entre electores sería muy bajo; (Kuschick, 2004). 
Desde el análisis de la Neurociencia, se manifestará que a través de campañas políticas, enfocadas en el funcionamiento del cerebro del elector, es posible cambiar la conducta electoral.

En relación a la Teoría de la Elección Racional que plantea que los ciudadanos escogen a sus candidatos haciendo un análisis previo de las posiciones políticas e ideológicas, las actuaciones pasadas de los partidos políticos, las propuestas programáticas y partiendo de ello, deciden por el candidato o partido que les otorga mayor beneficio, se demostrará que las campañas políticas enfocadas desde esta teoría, tendrán mayores probabilidades de fracaso, teniendo en cuenta que las apelaciones racionales son las que menos influyen activando los circuitos emocionales que regulan el comportamiento del elector.

\section{Capítulo 1.}

\section{Análisis Del Elector Desde La Neurociencia}

Como se ha descrito anteriormente, la neurociencia es la ciencia experimental que permite comprender el funcionamiento del cerebro humano y vislumbrar las bases del proceso de la toma de decisión humana, es imprescindible comprender que la neurociencia está abriendo una gran vía en el discernimiento de la naturaleza humana, el cerebro humano durante siglos ha sido por excelencia el gran desconocido, no obstante los avances en neurociencia y especialmente en neuropolítica están permitiendo conocer cada vez más lo que ocurre al interior de las personas en su condición de ciudadanos, electores o activistas.

Carlos Belmonte prestigioso científico del Instituto de Neurociencias de Alicante y experto en los mecanismos del dolor y del funcionamiento del cerebro, afirma que en un futuro cercano "Se podrá leer y manipular el cerebro como se quiera" (Rubí, 2012).

Las primeras pistas detectadas por Antonio Damasio en "El error de Descartes" describen a los seres humanos más emocionales que racionales y señala que el cerebro es más propenso a codificar los mensajes emocionales que las elaboraciones racionales. (Sánchez, 2012).

Varios gobiernos han estado implementando las técnicas de neuropolítica para internar comprender la forma de pensar y de procesar la información de sus ciudadanos y de esta manera persuadirlos, utilizar estrategias de comunicación política que conecte con su cerebro. Es de gran relevancia destacar que en el mes de Julio del año 2012 el gobierno francés anunció la creación de una oficina de neuropolítica dedicada a la aplicación de la neurociencia a la política pública.

El Dr. Olivier Oullier, Neurocientífico, director de esta unidad neuropolítica del gobierno francés afirma que las resonancias magnéticas funcionales muestran cómo opera el cerebro y la 
comunicación entre diferentes áreas, especialmente la interdependencia entre la profundidad emocional del cerebro y la parte racional, algo que llama "emoracionalidad".

Por otra parte el gobierno del Reino Unido tiene un equipo que utiliza conocimientos sobre los procesos cognitivos automáticos para inclinar a los ciudadanos hacia las decisiones que el gobierno considera favorables para sus intereses.

El conocimiento del cerebro humano permitirá comprender cada vez más lo que sucede al electorado cuando es expuesto a las campañas políticas, así cómo entender los factores más influyentes en su decisión política.

\section{1 ¿Cómo Piensan Los Electores?}

Es imprescindible destacar los planteamientos de neurocientíficos que han descubierto algunos factores en la forma de pensar de los electores.

Antes de hacer la descripción de cómo piensan los votantes según distintos autores neurocientíficos, es imperante referirse a algunos de los planteamientos del psicoanálisis, que serán de gran ayuda en la comprensión de la forma de pensar de los mismos.

Estudios del psicoanálisis señalan que existen sistemas múltiples de memoria en el individuo dentro de las cuales se encuentra la memoria de largo plazo y el inconsciente, denominados científicamente como memoria explícita e implícita respectivamente.

En la memoria explícita, que empieza a configurarse desde los primeros tres años de vida, se alojan los esquemas mentales, que son reconocidos por el inconsciente o memoria implícita, estos esquemas mentales, son estructuras derivadas de experiencias pasadas que interpretan experiencias actuales e influyen en la conducta de los individuos.

Ahora bien, los estudios de la ciencia cognitiva sostienen que los individuos piensan mediante marcos mentales, que son los esquemas mentales almacenados en la memoria de largo plazo, activados en los individuos de manera inconsciente,(Lakoff, 2007) estas estructuras mentales conforman el modo de ver el mundo, de acuerdo a las costumbres y valores, y responden más a la información que está en el plano de lo no consiente, Lakoff partiendo de este concepto sostiene que en muchas ocasiones las personas toman decisiones que aparentemente están en contra de su configuración personal. (Lakoff, 2007) George Lakoff en su libro “No Pienses En Un Elefante", realiza un análisis del comportamiento electoral de los americanos, partiendo de la hipótesis de que el éxito electoral está basado en la capacidad de estructurar todos los asuntos políticos en torno a los valores básicos asentados en la mentalidad de los ciudadanos, al mismo 
tiempo, en su estudio asegura que el partido republicano ha logrado mayor éxito electoral debido a que éste, en primera instancia ha dedicado años y billones de dólares en financiar investigaciones en torno a la forma de estructurar y comunicar sus ideas a la sociedad, desde lo cual han optado por utilizar en su estrategia política un lenguaje fuertemente afirmativo y articulado a los marcos mentales de la población americana, el cual está vinculado con valores y sentimientos morales, de esta forma la política conservadora americana ha sido capaz de convertir los valores familiares, en valores políticos (Lakoff, 2007).

Drew Westen, en sus estudios demostró que los republicanos han ganado más elecciones que los demócratas incluyendo presidentes, alcaldías, gobernaciones, y señala que la mayoría del pueblo americano coincide racionalmente con las ideas demócratas, su explicación es que los republicanos entienden mejor el funcionamiento del cerebro, el cual permite comprender que el voto es influido más por la emoción que por la razón. (Westen, 2007).

Por otra parte es imprescindible destacar los estudios del científico Alexander Todorov de Princetown University ${ }^{144}$ quien asegura que el voto muchas veces asumido como parte de un proceso lógico es influido por procesos automáticos e inconscientes.

En sus estudios demostró que los ciudadanos al ver la cara de los políticos pueden inferir si este es competente o no. En una de sus investigaciones mostró a distintas personas caras de políticos de Estados Unidos que ellos no conocían y les preguntaban quien les parecía más competente, este tipo de evaluación pareciera predecir alrededor de $70 \%$ del resultado de las elecciones.

Asegura que la cara es uno de los estímulos más complejos, existen estructuras cerebrales dedicadas al procesamiento de las caras, incluyendo el giro fusiforme y el surco temporal posterosuperior, son regiones que muestran una fuerte respuesta frente a las caras, pero también hay otras estructuras que también se activan frente a una cara como por ejemplo la amígdala, asegura que " tan pronto se ve una cara, el cerebro la detecta y extrae información valiosa como al edad, el género y los componentes afectivos de esa cara ${ }^{145 "}$

\subsection{El Cerebro Político}

Teniendo en cuenta los planteamientos anteriores, a continuación se hará una breve descripción de la estructura del cerebro y sus funcionalidades, lo cual permitirá comprender en mayor medida dichos postulados. Se describirán principalmente las áreas del cerebro que hasta ahora se han descubierto que tienen fuerte influencia en el comportamiento político del electorado.

\footnotetext{
144 Neurocientífico investigador búlgaro de la Universidad de Princetown.

145 Tomado de la Entrevista a Alexander Todovov realizada por el neurocientífico argentino Dr. Facundo Manes en el programa "Los Enigmas del Cerebro" disponible en: http://www.youtube.com/watch?v=gu8yPNv6bCQ
} 
El cerebro humano es el órgano más complejo del cuerpo, y por excelencia el gran desconocido, el Doctor Daniel Geffner jefe de la unidad de Neurología del Hospital General de Castellón, define el Cerebro como el órgano que permite pensar, sentir, desear y actuar, en el cual se asientan múltiples y diferentes acciones tanto conscientes como no conscientes, que permite al ser humano responder a un mundo en continuo cambio y que demanda respuestas rápidas y precisas (Geffner, 2011).

El sistema nervioso tiene una organización compleja que sigue planteando importantes retos a la ciencia, pese a los grandes avances de las últimas décadas. A continuación se describen las áreas influyentes del cerebro en la conducta electoral.

\section{Las Neuronas}

El cerebro está compuesto por billones de células nerviosas, llamadas neuronas, su propiedad más desarrollada es recibir, procesar y transmitir información mediante la emisión de impulsos bio-eléctricos a cientos de otras neuronas.

Las neuronas tienen una citoarquitectura específica que consiste en un cuerpo celular y en dos extensiones adicionales denominados "procesos", uno de ellos se llama axón y su función consiste en transmitir la información de una neurona a otras con las que tenga conexión. La otra extensión está formada por las dendritas y su función es la de recibir la información transmitida por los axones de otras neuronas, ambos procesos forman parte de los contactos especializados llamados sinapsis (Asociación Británica de Neurociencias, 2008)

El sistema de señales es doble: eléctrico y químico. La señal generada por la neurona y transportada a lo largo de su axón es un impulso eléctrico, esta señal es transmitida a otra célula mediante sustancias químicas que fluyen a través del contacto sináptico. Una neurona puede establecer entre 1.000 y 10.000 sinapsis, de manera que es informada por cientos o miles de neuronas y a su vez, ella informa a otras.

La mayoría de las sinapsis en las células de la corteza cerebral se encuentran situadas en las espinas dendríticas, que sobresalen de las dendritas como pequeños micrófonos en busca de señales, cuando una dendrita recibe uno de los mensajeros químicos liberados por uno de los axones al espacio que los separa, se crean en ella corrientes eléctricas en miniatura, estas corrientes pueden dirigirse a la célula y son llamadas excitatorias o bien, se mueven hacia fuera de la célula y entonces son llamadas inhibitorias. (Asociación Británica de Neurociencias, 2008:8) Todas estas corrientes positivas y negativas se acumulan en las dendritas y se dispersan posteriormente por el cuerpo celular. 
Si estas corrientes no crean suficiente actividad, al sumarse acaban muriendo y no ocurre nada más, sin embargo, si estas corrientes al sumarse superan el umbral de actividad, entonces la neurona enviará un mensaje a las otras neuronas vecinas. (Asociación Británica de Neurociencias, 2008)

La anterior descripción es la explicación de lo que asegura la Neurociencia, al afirmar que cada uno de los marcos mentales de los individuos están incrustados en la sinapsis del cerebro y en este sentido, para que un ciudadano logre identificarse con un argumento político, éste debe estar relacionado con los marcos que están en la sinapsis, de lo contrario, los anteriores entran y salen rápidamente (Lakoff, 2007)

A lo largo de la vida los ciudadanos se identifican con un marco de valores y una vez configurado, no renuncia a él, se encuentran presentes en las sinapsis del cerebro físicamente, bajo la forma de circuitos neuronales e influyen en las decisiones de los votantes de forma inconsciente. "cuando el mensaje político no encaja en los marcos, los marcos se mantienen y los hechos se ignoran" (Lakoff, 2007, p.110).

\section{La Empatía y Las Neuronas Espejo}

El principal objetivo de un político en su campaña es simpatizar con los electores, y persuadirlos para obtener la mayor votación posible y así ganar las elecciones. Ahora bien, es importante comprender ¿Qué se entiende por empatía? Lakoff la define como el proceso emocional que ocurre en el cerebro surgido a partir de sentir lo mismo que siente la persona que transmite el mensaje, por lo tanto si no existe emocionalidad en el político es imposible que los votantes la sientan y que estos puedan transmitir su mensaje.

¿Cómo ocurre el proceso de empatía política en el cerebro humano?

El proceso de empatía política se da gracias a un sistema de neuronas que están en el cerebro humano que son conocidas como Neuronas Espejo, fueron descubiertas a partir de un experimento en monos en el año 1996 con la investigación del neurocientìfico italiano Giacomo Rizzolatti, sus resultados indicaron que las células cerebrales de los monos se encendían no sólo cuando el animal ejecutaba ciertos movimientos sino que, simplemente con contemplar a otros hacerlo, también se activaban. (Rizzolatti, 2007)

El sistema de neuronas espejo en los seres humanos están ubicadas en la corteza frontal inferior cerca del área de broca o sistema límbico del cerebro, área del cerebro que controla el comportamiento y la interacción social. 
Las neuronas espejo tienen ciertamente la capacidad de proporcionar un mecanismo para comprender la acción, aprender por imitación, y la simulación imitativa del comportamiento de los demás, así como comprender las intenciones del otro.

Daniel Goleman, autor del libro "La inteligencia emocional", afirma que estas neuronas detectan las emociones, movimiento e incluso las intenciones de la persona que habla y reeditan en el cerebro del receptor el estado detectado, activando en él, las mismas áreas activas en el cerebro del interlocutor, creando un contagio emocional (Goleman, 2001).

El neurocientífico Marco Lacoboni sostiene que los humanos están "cableados para la empatía". En un estudio mediante Resonancia Magnética funcional (RMF), se descubrió que las áreas humanas de las que se suponía que contenían neuronas espejo también comunicaban con el sistema límbico o emocional, facilitando la conexión con los sentimientos de otra persona, probablemente reflejando estos sentimientos.

Se cree que estos circuitos neuronales constituyen la base del comportamiento empático, en el cual las acciones en respuesta a sentimientos como temor o esperanza son prácticamente instantáneas. (Lakoff, 2007).

\section{Hemisferios y Lóbulos}

El cerebro está dividido en dos hemisferios unidos por varios puentes, el mayor es el cuerpo calloso con millones de fibras nerviosas que comunican ambos lados. Cada hemisferio cerebral tiene unos territorios definidos como lóbulos cerebrales, delimitados por grandes surcos. Los lóbulos son: Frontal, parietal, temporal y occipital.

\section{Lóbulo Temporal}

El lóbulo temporal es el asiento de los últimos peldaños de procesamiento auditivo, así como el lugar donde, en su cara medial, se asientan importantes estructuras de la memoria, el hipocampo y del sistema emotivo inconsciente, llamado el sistema límbico.

\section{El Sistema Límbico}

El sistema límbico es un complejo conjunto de estructuras que se hallan por encima y alrededor del tálamo y justo bajo la corteza. Incluye el hipotálamo, el hipocampo, la amigdala y muchas otras áreas cercanas.

El sistema límbico es un sistema formado por varias estructuras cerebrales que gestionan respuestas ante estímulos emocionales, está implicado en las emociones y en la habilidad de ponerse en el lugar de los demás, esta parte del encéfalo recibe el impulso primario para 
transferirlo más tarde a la corteza cerebral, en concreto a la parte temporal y pre frontal, ésta área del cerebro controla y regula los impulsos.

\section{Amígdala}

Dentro del sistema límbico, existe un centro de operaciones en el cual se controla las repuestas emocionales, éste es denominado amígdala y desde esta, parten los mecanismos para determinar si el estímulo que llega es positivo o negativo y el tipo de emoción que se genera.

Según los estudios realizados por Drew Westen, quien cita en su libro al neurocientífico Joseph LeDoux, la amígdala es la estructura cerebral que llama más la atención en el área de la neuropolítica (Westen, 2007).

La amígdala está envuelta en el proceso emocional del votante, desde la identificación y respuesta a la expresión emocional, hasta agregar significado emocional a eventos, creando la intensidad de la experiencia emocional para generar y unir sentimientos.

Westen asegura que la amígdala responde desde el inconsciente del individuo, la presentación rápida de un estímulo amenazante subliminalmente puede permitir la activación de la amígdala, lo que sugiere un sistema emocional que está constantemente procesando información emocionalmente relevante más rápido de lo que conscientemente pueda registrarlo. (Westen, 2007)

El hecho de que las personas puedan registrar experiencias emocionales fuera del consciente tiene una importante implicación en el campo electoral. Según varios de los experimentos realizados por Westen, muchos de los avisos publicitarios y los componentes de un auditorio, la música de fondo, que generalmente son aspectos de los cuales la audiencia no está consciente, pueden ser herramientas subliminales que activan circuitos neuronales de empatía en los electores y son elementos que son procesados en el sistema límbico. (Westen, 2007)

El neurocientifico americano Raymond Dolan en su investigación estudió las áreas cerebrales que registran las expresiones faciales de las emociones. Por ejemplo, la contemplación de un rostro miedoso activa en el cerebro la amígdala y despierta emociones semejantes, la información se procesa sin que el estímulo desencadenante penetre en la conciencia.

La amígdala modula procesos cognitivos y sensoriales a través de conexiones neuronales con otras áreas, como el hipocampo y establece conexiones con el estriado y con el córtex orbitofrontal (COF) a través de numerosas vías nerviosas. (Morris J.S, Raymond Dolan \& A Ohman, 1998). 
El giro fusiforme elabora las propiedades estáticas del rostro, examinando la identidad sin preocuparse de su expresión emocional. (Morris, Dolan \& Ohman, 1998) El surco temporal superior (STS), es una estructura situada por encima de los centros visuales que procesan los aspectos dinámicos del rostro y que permite adquirir información sobre la persona. (Franz, Ford \& Werner, 2007)

\section{Capítulo 2. Storytelling, Herramienta De Persuasión Política, Entendida Desde La Neuropolítica} El storytelling es una técnica moderna que reconoce la influencia en la emocionalidad y los marcos mentales de las audiencias, se define como la técnica de transmitir un discurso o mensaje a través de una historia en forma de metáfora (Salmon, 2008).

Christian Salmon en su obra Storytelling, La Máquina De Formar Historias y Formatear Las Mentes, manifiesta que el relato y la capacidad para contar una historia, pueden resultar mucho más efectivo que cualquier intento de convencer al oyente a través de la retórica argumentativa sostenida en juicios racionales. (Salmon, 2008)

Varios autores se han referido al análisis del Storytelling como herramienta de comunicación y persuasión efectiva. Jerome S. Bruner Psicólogo, experto en lenguaje, asegura que los seres humanos tienen una disposición inherente o predisposición de organizar experiencias en forma de historia: en puntos de vista, características, intenciones, estructuras argumentales secuenciales, señalando que la evidencia más clara, está en la capacidad de los niños para construir a través del dialogo con sus compañeros, imaginarios que los conectan y que le permiten al mismo niño desarrollar su pensamiento (Bruner, 2003).

Otro autor necesariamente a mencionar es el psicólogo cognitivo y lingüista Steven Pinker quien afirma que "100.000 años de evolución en relato, han incorporado en la instrucción del código genético humano la capacidad de cablear el cerebro para pensar en términos de un relato". Su argumento más fuerte y por el que se ha ganado grandes debates con evolucionistas modernos, es que el lenguaje es un "instinto" o una adaptación biológica modelada por la selección natural, manifiesta que la interacción a través del lenguaje es propia de su naturaleza biológica, por tanto también su capacidad para usarlo en la construcción de su realidad (Pinker, 1997).

Ahora bien, ¿cómo se explica la efectividad del storytellling en el discurso político? El psicoanálisis es una de las bases teóricas que determina la efectividad de una historia en los imaginarios de los seres humanos. El psicoanálisis ha demostrado que el inconsciente se vuelve el escenario ideal donde se da cabida a deseos, dramas, ansiedades y todo aquello que la realidad no permite. 
El neurolingüística George Lakoff, sostiene que todas las palabras que se transmiten están definidas en relación a marcos preconcebidos, es decir, cuando el ciudadano escucha una palabra, en su cerebro se activa el marco o colección de marcos que le permiten conectarse con el individuo que transmite el mensaje, por lo tanto el discurso debe involucrar las palabras y los conceptos que encajan con los marcos mentales de las audiencias, para ello el primer paso es identificar los enmarcados que tienen los distintos segmentos de la población electoral. (Lakoff, 2008)

El ex presidente estadounidense Ronald Reagan, comprendió este concepto, él tenía claro que los obreros eran estrictos en su casa, basado en esa información estructuró un discurso político dirigido a este segmento, a través de metáforas de la casa y la familia, logrando que los obreros extrapolasen los valores de la casa a (Salmon, 2008)

Los principales planteamientos de Storytelling, han sido definidos por el científico cognitivo George Lakoff, quien afirma que las palabras tienen la capacidad de evocar los marcos que están en la sinapsis del cerebro, los cuales inmediatamente se traducen en imágenes en la mente del receptor, por lo tanto, es necesario construir un mensaje capaz de transmitir las ideas que puedan conectarse con los ciudadanos y de manera inconsciente causar empatía entre el ciudadano y el político.

La neurociencia afirma que la misma región del cerebro usada para ver, también es usada para imaginar y soñar, Lakoff asegura que la imaginación es una simulación mental, así como el significado del lenguaje, basado en lo que el cerebro puede transmitir de lo escuchado.

El lenguaje actúa generando circuitos neuronales que crean imágenes o simulación de experiencias en el inconsciente. (Lakoff, 2008)

\section{Storytelling y Las Metáforas}

Lakoff, estudioso de las metáforas, define las metáforas como estructuras mentales que son independientes del lenguaje, pero que pueden ser expresadas y activadas por el lenguaje, asegura que "Las metáforas duermen en nuestro cerebro en espera de que alguien las despierte" (Lakoff, 2007), en este orden, cuando un político utiliza metáforas en su discurso es capaz de activar circuitos neuronales en el cerebro que inmediatamente crean una conexión entre el elector y el político.

George Lakoff y Mark Johnson, en su trabajo "Metaphors we live by", señalan que el lenguaje cotidiano está lleno de metáforas, argumentan que la comprensión de la metáfora se basa en las experiencias sensoriales y motoras de los individuos. (Lakoff, 1980) 
Ahora bien, una reciente investigación de Journal of Brain and Language que el opérculo parietal, región del cerebro que se activa en la detección de la textura a través del tacto, también se activa cuando una persona escucha una frase con una metáfora. La misma región no se activa cuando una sentencia similar expresa el significado de la metáfora que se escucha. El autor de la investigación el Doctor Krish Sathian, MD, PhD, profesor de neurología, medicina de rehabilitación, y psicología en la Universidad Emory se refirió a estos resultados agregando que "Las metáforas activan áreas de la corteza cerebral involucradas en la respuesta sensorial, aun cuando las metáforas sean bastante familiares"

Por otra parte, científicos cognitivos han reconocido extensamente la narración como principio básico de la organización de la memoria. Según el Dr. John Medina biólogo molecular e investigador, "Los datos puros, sin contexto son muy difíciles de retener a largo plazo para el cerebro".

El neurocientífico cognitivo Michael Gazzinga se refiere al éxito del storytelling afirmando que la precisión de lo narrado no es el tema central, si no, la coherencia, que proporciona el relato, que permite que las audiencias permanezcan conectadas con el político, capten el mensaje y sientan una conexión inconsciente al sentir que éste captó su atención, además de las emociones que evocan los relatos ${ }^{146}$.

Por otro lado, según un estudio publicado en Proceeding of the National Academy of Sciences, cuando alguien cuenta una historia, el cerebro y el del narrador se sincronizan sutilmente, activándose en los receptores las mismas áreas cerebrales que están en la mente del narrador, en este sentido, contar y escuchar historias es una forma directa de conexión emocional con los demás ${ }^{147 .}$

Por otra parte el consultor Frank Luntz, autor del libro, Words that Works, en 2006, aseguró que el mensaje exitoso no debe estar basado en lo que dice el político, sino en lo que la gente escucha, es decir, los ciudadanos escuchan partiendo de sus marcos mentales y no de las ideas políticas que el político está pretendiendo transmitir, en este orden Luntz, también asegura que el uso correcto del lenguaje comienza por la ideas políticas pero relacionadas con los marcos mentales de las audiencias. (Luntz, 2006)

Por último, el leguaje es la puerta que conduce a la mente, éste organiza y propicia el acceso al sistema de conceptos y marcos mentales, el lenguaje es un instrumento de creatividad y poder,

\footnotetext{
146 Tomado de Entrevista a Michael Gazzinga: Your Storytellin Brain En: http://www.youtube.com/watch? v=3k6P5JiNzrk

147 Tomado del Artículo Storytelling y Gramificaciòn, Revista Elogia. En: http://www.elogia.net/blog/storytelling- gamificationentornos-transmedia/
} 
una herramienta para conectar con los individuos y alinearse con ellos, también es considerado una fuerza de cohesión social o de separación, en términos de Lakoff, el lenguaje puede evocar en los ciudadanos lo mejor o lo peor.

\section{CONCLUSIONES}

La neuropolítica, y el psicoanálisis develan hoy puntos de álgida relevancia que los políticos y sus estrategas deben contemplar en la estrategia que rige sus campañas políticas.

En primera instancia, los aportes de la neurociencia para el desarrollo de una campaña política exitosa, permiten comprender que la comunicación política del candidato puede causar excitación neuronal o inhibición neuronal, dependiendo del lenguaje, los gestos, y las herramientas que éste usa, cuando éstos corresponden a los marcos mentales que están incrustados en la sinapsis del cerebro de los electores, las neuronas se excitan e inmediatamente transfieren los cirquitos eléctricos y químicos a las demás células nerviosas, causando conexión instantánea entre el político y las audiencias.

Para que el político pueda causar excitación neuronal debe tener en cuenta varios aspectos que la neurociencia y el psicoanálisis ha demostrado:

\section{Los seres humanos piensan mediante marcos.}

Los seres humanos piensan mediante marcos preconcebidos que se han configurado en la memora explícita activados por la memoria implícita o inconsciente y que están incrustados en la sinapsis del cerebro, por lo tanto los políticos deben estar en la capacidad de estructurar su campaña política en torno a los marcos preconcebidos de los ciudadanos, estos marcos son los valores, creencias preexistentes y cultura, asentados en la mentalidad de los ciudadanos, Charles Pierce, Jhon Dewey y la escuela de Michigan tuvieron acercamientos teóricos con estos postulados.

Por lo tanto para que una campaña política sea exitosa, ésta debe iniciar con el estudio detallado de los marcos, preconceptos y valores que rigen la sociedad y unir el universo de los públicos en torno a los valores comunes de la sociedad, esto no quiere decir, que no deba realizar una segmentación de los votantes, efectivamente el político debe hacerlo y debe conocer los marcos que están en cada uno de los segmentos.

\section{El comportamiento electoral está influenciado más por factores emocionales que por elementos racionales:}

Al estudiar el sistema límbico del Sistema Nervioso Central, se pudo comprender que los seres humanos percibimos mejor los acontecimientos cargados de sentimientos que los hechos 
neutros y que los estímulos emocionales captan más la atención y son procesados por el cerebro con mayor precisión que los estímulos racionales, ya que la amígdala es el área del cerebro que al activarse permite que los ciudadanos puedan agregar significado emocional a elementos como la música de fondo, la decoración del escenario, el tono de la voz, los movimientos del candidato, las metáforas y otros elementos emocionales, crean la intensidad de la experiencia emocional para generar y unir sentimientos. Cuando el ciudadano entra en contacto con el candidato, la amígdala determina si el estímulo que éste está impulsando es positivo o negativo y si causa apatía o empatía, miedo o seguridad, frustración o esperanza.

Teniendo en cuenta que el comportamiento electoral está influenciado por factores biológicos que tienden más a la emocionalidad que a la racionalidad, el candidato debe estructurar su campaña política partiendo en primera instancia de las ideas racionales políticas pero llevarlas al plano de lo emocional, que es el plano del inconsciente, para que éstas puedan penetrar en el terreno mental de los electores y de esta manera influir en su conducta.

\section{El poder la Imagen política en el comportamiento Electoral}

Este estudio permitió comprender el papel fundamental que juegan las neuronas espejo en la empatía política. Las emociones, movimientos e incluso las intenciones que proyecta el candidato, se reeditan en el cerebro del elector activando en éste, las mismas áreas activas en el cerebro del candidato, creando un contagio emocional, por lo tanto, a través del sistema de neuronas espejo, el elector al ver y escuchar al candidato, se conecta en primera instancia con sus marcos mentales, éste adopta los sentimientos y emociones que éste refleja, puede sentir lo que este siente e incluso transmitirlo, es por ello, que el candidato político debe ser capaz de transmitir sentimientos y emociones positivos y competencia en su mensaje.

Por otra parte, las áreas como el giro fusiforme, el surco temporal superior y la amígdala permiten comprender las expresiones gestuales de los candidatos y percibir si es una persona incompetente, débil o insegura, o por otra parte si es competente, fuerte y decidida, por lo tanto, el candidato debe realizar un trabajo fuerte y minucioso en su imagen corporal, para que refleje expresiones positivas y no negativas. Muchos candidatos se someten a cirugías plásticas para que sus rostros parezcan más amables, simpáticos y competentes.

\section{El poder del lenguaje Político}

El lenguaje político tiene un poder altísimo en el comportamiento electoral, en la capacidad de evocar los marcos mentales de los ciudadanos. 
El mensaje de campaña es el factor que hace de una campaña que sea fuerte o débil, éste es la esencia de la propuesta electoral.

Teniendo en cuenta los aportes de la Neurociencia y el Psicoanálisis, materializados en la herramienta del Storytelling, es imprescindible tener en cuenta que a la hora de estructurar el mensaje de campaña, este corresponda con los marcos mentales, valores, sentimientos y coyuntura.

Por otra parte, la neurociencia permitió comprender que los seres humanos entienden en términos de metáforas, ya que los seres humanos tienen una disposición inherente o predisposición de organizar experiencias en forma de historia, en puntos de vista, características, intenciones, estructuras argumentales secuenciales, por tanto, los políticos deben realizar sus discursos en forma de relato, éste capta la atención permanente de los electores, crea recordación, mientras que los datos puros sin contexto son muy difíciles de retener a largo plazo para el cerebro, asimismo, el relato permite una conexión con sentimientos y metáforas propias receptor, generando empatía con el interlocutor.

Por otra parte, los medios de comunicación son capaces de influir completamente en la conducta del votante. La campaña publicitaria logra evocar los marcos conceptuales y por lo tanto los circuitos neuronales en los individuos, en este orden, teniendo en cuenta que los electores son seducidos por la emocionalidad, la estrategia publicitaria debe ir en vía de evocar sentimientos.

El hecho de que las personas puedan registrar experiencias emocionales fuera del consciente tiene una importante implicación en el campo electoral, muchos de los avisos publicitarios y los componentes de un auditorio, la música de fondo, que generalmente son aspectos de los cuales la audiencia no está consciente, son herramientas subliminales que activan circuitos neuronales de empatía en los electores.

En definitiva, el éxito de una campaña política está en saber comunicar las ideas políticas teniendo en cuenta el funcionamiento del cerebro.

\section{REFERENCIAS BIBLIOGRÁFICAS}

ALMOND, G.; Dahl, R.; Downs, A; et al. (1992). Diez textos básicos de Ciencia Política. Editorial Ariel, colección Ciencia Política, España.

ARNOLETTO, E. J. (2007). Curso de Teoría política. Editado por Eumed.net. Edición electrónica. Texto completo en: www.eumed.net/libros/2007b/300/. 
Stefany Arteaga Márquez

ASOCIACIÓN BRITÀNICA DE NEUROCIENCIA (2008) La Ciencia del Cerebro, una introdución para jóvenes estudiantes. The Sherrington Buildings Ashton Street LiverpoolL 693 GE UK 2003 ISBN: 09545204-0-8

BARTELS, Larry M, (2008). The Study of Electoral Behavior, Princeton University.

BRUNER, Jerome (2003): La fábrica de historias: Derecho, literatura, vida. Buenos Aires, pag. 2032

COMBS, James E. y Dan Nimmo (1998), La nueva propaganda, Diana, México.

CORTINA, Adela, (2012) Neuroéticay Neuropolítica, Sugerencias para la educación moral. Editorial Tecnos.

CRUZ, Olga Rodríguez (2009). Factores que influyen en la Determinación electoral, Una visión desde la comunicación política, Tesis Doctoral. En:

http://148.206.107.15/biblioteca_digital/articulos/12-390-5869dbj.pdf

DAMASIO, Antonio R. (2011) El Error De Descartes, Editorial Destino.

DOWNS, Anthony. (1992) Teoría Económica de La Acción Política En Una Democracia.

GOLEMAN, Daniel (2001) La Inteligencia Emocional. Editorial Kairós.

MORRIS, A. Öhman \& R. J. Dolan (1998) Conscious and unconscious emotional learning in the human amygdala Nature, Vol 393(6684), Jun 1998, 467-470.

KANDEL Eric. (2000). Principles of Neural Science, Fourth Edition. McGraw- Hill.

KUSCHICK, Murilo, (2004) Teorías Del Comportamiento Electoral y Algunas De Sus Aplicaciones. Revista mexicana de ciencias políticas y sociales, enero-abril, año/vol. XL VI, numero 190 Universidad Nacional Autónoma de México, Distrito Federal, México pp.47-72.

KATZ, Elihu; Lazarsfeld, Paul F. (1960) La influencia personal, Sociología del poder.

LAKOFF George, (2007) The Political Mind, A Cognitive Scientit'S Guide to Your Brain and Its Politics. 
Stefany Arteaga Márquez

LAKOFF, George, (2007) No Pienses en un Elefante, Lenguaje y debate político EditorialComplutense, S.A

LAKOFF, George, (1980) and Mark Johnson. Metaphors We Live by. Chicago: University of Chicago.

LEARY, Timothy, Anton Wilson, A Koopman, Girlberton Daniel:Neuropolitics: (1977) The Sociobiology of human metamorphosis.

LIPPMANN, Walter (1956), Public Opinión, Macmillan, Nueva York.

LUNTZ, Frank, (2006). Words that work, it is not what you say, it's what people hear.

MCADAMS, D.P. (1993) The Stories We Live By New York: The Guilford Press.

MARTín Salgado, Lourdes (2002), Marketing político, Arte y ciencia de la persuasión en democracia, Paidós, España.

PEÑAS, F Olga. (2010). El Enfoque Conductista En La Ciencia Política. T.O., Esp. Políticas Públicas, Mag. Salud Pública, Doctorado en Estudios Políticos. Publicado En:

http://www.bdigital.unal.edu.co/1717/2/olgaluzpenasfelizzola.20102.pdf

PINKER, Steven (1997) How the Mind Works. New York: W.W. Norton. 1997.

RIZZOLATTI, G. et al. (2007). Neuronas espejo. Investigación y Ciencia. Enero, 14-21.

SALMON, Christian. (2008). La Máquina de Contar Historias y Formatear Las Mentes. Editorial Peninsula, España.

OLSON, Mancur (1971). The Logic of Collective Action, Harvard University Press, Cambridge.

WESTEN, Drew (2007). The Political Brain. The Role of Emotion in Deciding the Fate of the Nation. New York Public Affairs.

\section{Artículos}

FERNÁNDEZ, Lago (2012) Storytelling y Gramification en Entornos transmedia. En: http://www.elogia.net/blog/storytelling-gamification-entornos-transmedia/ 
Stefany Arteaga Márquez

GUTIÉRREZ-Rubí, Antoni (2009).La neuropolítica: conocer el cerebro para liderar las ideas, En Revista de la Fundación Rafael Campalans (Noviembre 2009)

GUTIÉRREZ-Rubí, Antoni (2010).Micropolítica: Ideas para cambiar la comunicación política En Revista "Ejecutivos" (Julio 2010)

LISTON, Delores D. (1994). Story-Telling and Narrative: A Neurophilosophical Perspective. En: http://www.eric.ed.gov/ERICWebPortal/search/detailmini.jsp? nfpb=true\& \&ERICExtSearch S earchValue 0=ED372092\&ERICExtSearch SearchType 0=no\&accno=ED372092

National Academy of Science of UK. (2011). Neurosciencie: implications for education and lifelong learning. The Royal Society En:

http://royalsociety.org/uploadedFiles/Royal Society Content/policy/publications/2011/429497 5733.pdf

SÁNCHEZ, José María. (2012) La Neuropolítica y La Salud Pública Revista esalud.com Vol.

8 , No 31 (2012) En: http://www.revistaesalud.com/index.php/revistaesalud/article/view/559

\section{Enlaces De Interés:}

Entrevista a Alexander Todovovrealizada por el neurocientífico argentino Dr. Facundo Manes en el programa "Los Enigmas del Cerebro" disponible en:

http://www.youtube.com/watch?v=gu8yPNv6bCQ

Entrevista a Michael Gazzinga: YourStorytellinBrain En:

http://www.youtube.com/watch?v=3k6P5JiNzrk

Entrevista a Adela Cortina sobre su libro "Neuroética y Neuropolítica” (Fundación International Studies, 21.10.2011)

Introducción a la historia de las Neurociencias hasta finales del Siglo XIX, publicado en: http://www.neurociencias.org.es/intro.php 